\title{
Pediatric spinal deformities
}

\author{
Gregory C. Wiggins, M.D., Christopher I. Shaffrey, M.D., Mark F. Abel, M.D., And \\ ARNOLD H. MENEZES, M.D. \\ Department of Neurosurgery, United States Air Force, Travis Air Force Base, Fairfield, California; \\ Department of Neurosurgery, University of Washington School of Medicine, Seattle, Washington; \\ Department of Orthopeaedic Surgery, University of Virginia School of Medicine, Charlottesville, \\ Virginia; and Department of Neurosurgery, University of Iowa College of Medicine, Iowa City, Iowa
}

\begin{abstract}
Pediatric spinal deformity results from multiple conditions including congenital anomalies, neuromuscular disorders, skeletal dysplasia, and developmental disorders (idiopathic). Pediatric spinal deformities can be progressive and cause pulmonary compromise, neurological deficits, and cardiovascular compromise. The classification and treatment of these disorders have evolved since surgical treatment was popularized when Harrington distraction instrumentation was introduced.

The advent of anterior-spine instrumentation systems has challenged the concepts of length of fusion needed to arrest curvature progression. Segmental fixation revolutionized the surgical treatment of these deformities. More recently, pedicle screw-augmented segmental fixation has been introduced and promises once again to shift the standard of surgical therapy. Recent advances in thoracoscopic surgery have made this technique applicable to scoliosis surgery.

Not only has surgical treatment progressed but also the classification of different forms of pediatric deformity continues to evolve. Recently, Lenke and associates proposed a new classification for adolescent idiopathic scoliosis. This classification attempts to address some of the shortcomings of the King classification system.

In this article the authors review the literature on pediatric spinal deformities and highlight recent insights into classification, treatment, and surgery-related complications.
\end{abstract}

KeY WoRdS - scoliosis • pediatric neurosurgery - spinal deformity • natural history

In the pediatric age group, spinal deformity results from congenital anomalies, neuromuscular disorders, neurofibromatosis, connective tissue disorders, and skeletal dysplasia (including dwarfism syndromes)., 3,76,108 Idiopathic scoliosis, the most common deformity, is a diagnosis made after excluding generalized syndromes and congenital or inflammatory causes. Each category of spinal deformity has characteristic features that are dictated by the pathophysiology of the underlying condition.

Scoliosis, kyphosis, and lordosis refer to deviations from normal spinal alignment. Scoliosis, curvature in the coronal plane, is also associated with transverse rotation, as well as with pathological lordosis or kyphosis (Fig. 1). ${ }^{30-32,34,38}$ Therefore, the descriptive terms lordoscoliosis and kyphoscoliosis are frequently used to characterize the $3 \mathrm{D}$ character of the deformity. When more than one pathological curvature exists along the length of the spine, the primary curve is designated on the basis of its size and rigidity. The secondary curve, even if compensatory, may be rigid or have a "structural" component. In planning

Abbreviations used in this paper: AIS = adolescent idiopathic scoliosis; $\mathrm{AP}=$ anteroposterior; $\mathrm{MR}=$ magnetic resonance; $\mathrm{RVAD}=$ rib-vertebra angle difference; $\mathrm{SCI}=$ spinal cord injury; $\mathrm{VB}=$ vertebral body; $3 \mathrm{D}=$ three-dimensional. surgery one must take into account the magnitude and flexibility of all the curves in all three planes. ${ }^{8,13,39,61,97}$ Treatments, including brace therapy and surgery, are indicated for progressive deformity or deformities destined to progress. The type of treatment, however, is ultimately determined by the diagnosis and severity of the condition. . $^{18,19,21,43,44,46,75,76,86,108,112,117,121}$

\section{GROWTH OF THE SPINE}

Pediatric spinal deformities are usually not present at birth. They all progress, however, in proportion to spinal growth, ${ }^{37,72,74}$ and, therefore, anticipating and controlling the growth potential of the vertebral elements comprising the deformity is the key to successful management. Two periods of rapid growth occur in children: between birth and 3 years of age and during adolescence. ${ }^{37}$ The growth spurt ends at a skeletal age of 14 years, or approximately 1.5 years after menarche in girls, and at age 18 in boys. According to Dimeglio and Bonnel, ${ }^{37}$ in the adolescent growth spurt the thoracic spine grows $1.2 \mathrm{~cm} /$ year, whereas the lumbar spine grows $0.6 \mathrm{~cm} /$ year. Based on these data, one can calculate the effect of fusing spinal segments during puberty. As pointed out by Winter, ${ }^{114}$ a short, straight spine is preferable to a severe scoliosis that compromises cardiopulmonary or neurological function.

The prediction of spinal growth in the peri- or intrapu- 


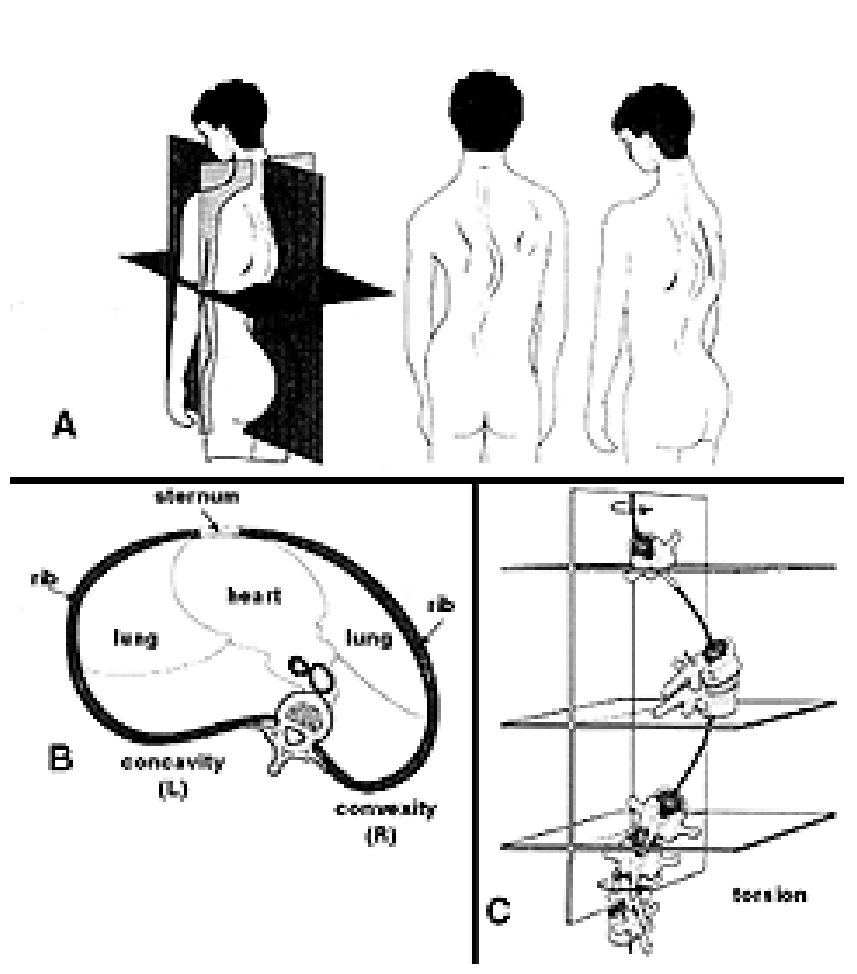

Fig. 1. A: Idiopathic scoliosis is a 3D deformity, typically associated with thoracic hypokyphosis or lordosis. B: Over time, deformation of the thoracic cage causes the right posterior rib angle to become more prominent and the left breast to project forward. $\mathrm{C}$ : The end vertebrae of the scoliosis are most tilted, whereas the apical vertebrae are most rotated and laterally translated. Typically, a left lumbar curve is present in which the vertebrae are rotated in the opposite direction. Image used with permission from Elsevier.

bescent period is based on physical and radiographic examinations. ${ }^{71,72}$ The Risser sign, a radiographic method for estimating the state of bone maturity, is based on the appearance and fusion of the iliac apophysis (Fig. 2). ${ }^{71,93}$ Stages 1 through 4 correspond to the sequential ossification of each quarter of the iliac crest from posterior to anterior. In general, spinal growth is complete when Risser Stage 4 is reached. The estimation of the growth remaining is an integral part of planning all aspects of treatment in cases of pediatric spinal deformities.

\section{IDIOPATHIC SCOLIOSIS: EARLY AND ADOLESCENT ONSET}

\section{Epidemiology and Classification}

Idiopathic scoliosis has a familial tendency and a bimodal frequency distribution. ${ }^{124}$ There is an early-onset variety in which the majority of cases occur in infancy, and a second major peak occurring during adolescence. Accordingly, the Scoliosis Research Society adopted a scoliosis classification that is based on the age of onset: infantile scoliosis, 0 to 3 ; juvenile scoliosis, 3 to 9 ; and adolescent scoliosis, older than 9 years of age. ${ }^{46}$ By far the most common variety is AIS. Because the cause of idiopathic scoliosis is not known, its diagnosis is not made until all other causes of scoliosis have been excluded. ${ }^{47,60,71}$

The prevalence of AIS varies depending on the magni-

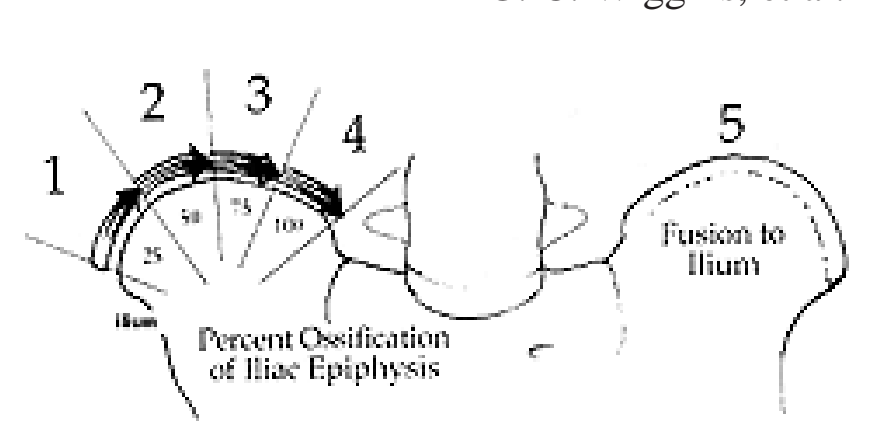

Fig. 2. The Risser stage of iliac ossification can be used to estimate remaining maturity and growth. Image used with permission from Elsevier.

tude of the curvature used for the diagnostic criterion. ${ }^{17,106}$ If based on a curve of $10^{\circ}$, as has been accepted as the lower limit to be diagnostic for idiopathic scoliosis, 2 to $3 \%$ of the adolescent population (10-16 years of age) have scoliosis. The prevalence for curves in excess of $20^{\circ}$ is 0.3 to $0.5 \%$, whereas that of curves in excess of $40^{\circ}$ is $0.1 \%$. Early-onset idiopathic scoliosis, in which a curvature develops before the age of 8 years, is much less common but is associated with graver physiological consequences. ${ }^{123}$ Because curvature progression is related to growth potential, the younger the patient is when the curve develops, the larger is the deformity at maturity. Deformities developing in children before the age of 5 years have the potential of exceeding $100^{\circ}$ in magnitude, producing detrimental effects on the developing cardiopulmonary system. ${ }^{35,59}$ Consequently, treatment approaches are recommended in lieu of patient age and the magnitude of deformity. ${ }^{40,95}$

\section{Adolescent Idiopathic Scoliosis}

Typically, AIS occurs in girls. The incidence in boys is approximately one tenth that in girls. ${ }^{34,124}$ The typical curvature pattern is a right thoracic curve with an accompanying fractional left lumbar curve. ${ }^{45}$ The symptoms are minimal, and the patients present because of the deformity. Screening programs at schools have traditionally been a means by which these curves are identified; however, there is no evidence that they have led to changed outcomes. ${ }^{17}$

The natural history of AIS has been studied extensively by Weinstein alone, ${ }^{106,107}$ with Ponseti, ${ }^{109}$ and with colleagues $^{110}$ who followed the same group of patients for over 40 years, as well as by Collis and Ponseti. ${ }^{26}$ Factors that relate to progression of idiopathic curves include physiological age, sex, curve magnitude, and curve type. ${ }^{21,106}$ Progression is more likely in the younger patient, girls, patients with larger curves, and in patients with double curves. For example, in a girl with a curve between 20 to $29^{\circ}$ and at a Risser stage of 0 to 1 , the chance of curve progression will be $68 \%$, whereas if the Risser stage were 2 to 4 , the risk would be $23 \% .{ }^{21}$ During adolescence, curves typically progress a mean of $1 \%$ month, and curves in excess of $50^{\circ}$ are associated with a high risk of progression even after skeletal maturity. ${ }^{7,109}$ It is of note that the relationship of symptoms to magnitude of the curvature is not so straightforward, and many patients with severe curves exhibit few symptoms. Lumbar curves, however, are more likely to cause back pain. Finally, there is a 
significant inverse relationship between the pulmonary vital capacity and magnitude of thoracic scoliosis. Thoracic curves greater than $70^{\circ}$ are associated with a vital capacity less than that predicted for size..$^{1,24,110}$

The physical examination should exclude other causes of scoliosis. ${ }^{72,79}$ Atypical presentations requiring further MR imaging evaluation include left thoracic curves, those progressing more rapidly than expected, and those associated with neurological findings (Fig. 3) ${ }^{96}$ Furthermore, the presence of pain, especially at night, suggests a diagnosis other than idiopathic scoliosis.

King, et al., ${ }^{61}$ developed an important classification system for AIS after examining anterior radiographs obtained in 149 cases. A center sacral line was drawn on the standing AP radiographs through the center of the sacrum and perpendicular to the iliac crests. The vertebrae bisected most closely by this line were designated as "stable" (Fig. 4). The classification, which includes five curve patterns, is based on the number, flexibility, and deviation of the curves from the midline (Fig. 5). Vertebral levels included

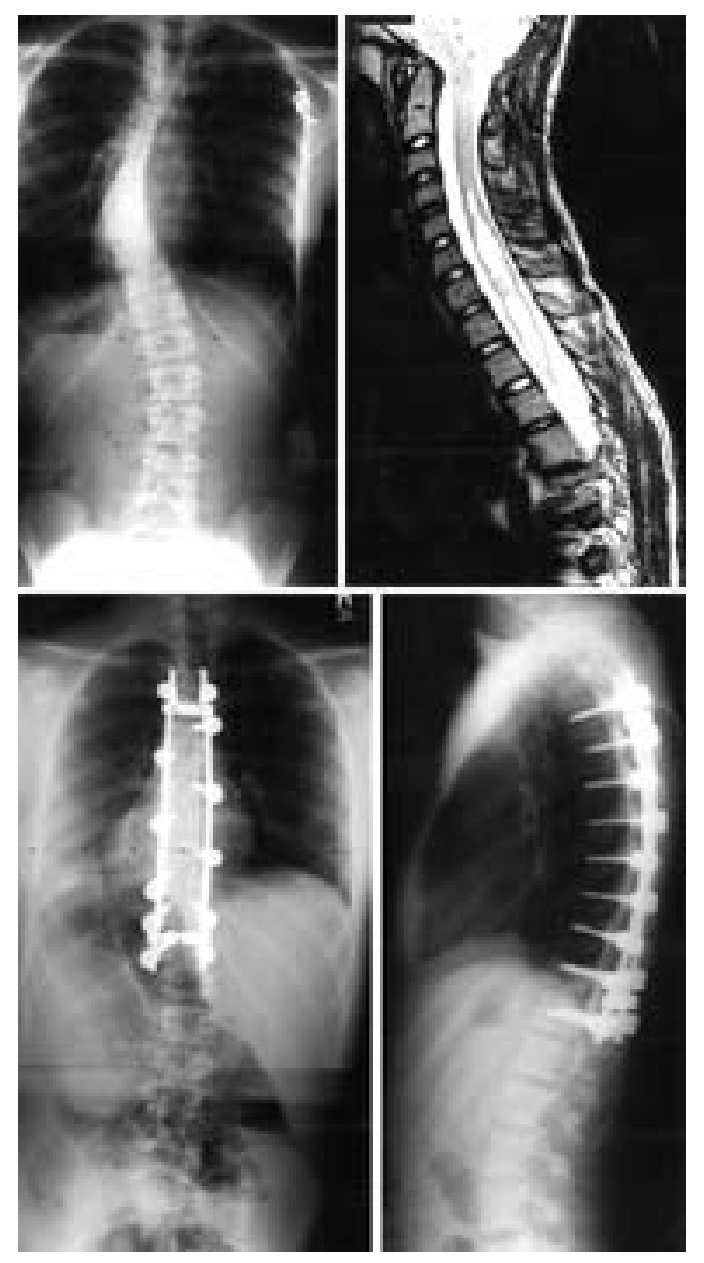

Fig. 3. Imaging studies obtained in a 12-year-old girl with progressive myelopathy and King Type II scoliosis. Upper Left: Preoperative AP radiograph. Upper Right: Sagittal MR image revealing a cervical syrinx that was drained. After this, she underwent T4-12 thoracic pedicle screw-assisted fusion. Lower Left and Right: Postoperative AP and lateral radiographs demonstrating good curve correction with maintenance of sagittal balance.

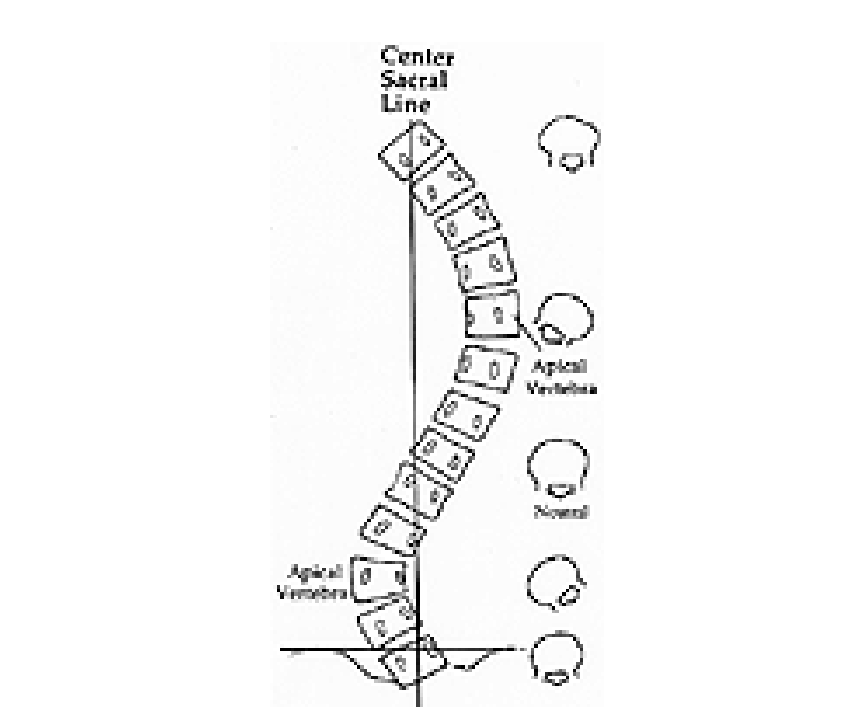

Fig. 4. The center sacral line is perpendicular to a horizontal line across the iliac crest, passing vertically through the sacral spinous processes. Vertebrae bisected by the center sacral line are designated as the stable vertebrae. Image used with permission from Elsevier.

in the fusion will depend on the deformity pattern, severity, and flexibility of the curves.

Ideally, a classification system is used to assess a clinical entity, enable surgeons to recommend treatments, and allow comparison of different treatment methods. ${ }^{28}$ The King classification system has been used extensively. Because it was based only on AP radiographs, however, scoliosis was not seen as a 3D deformity. Intraobserver and interobserver reliability has been reported as only poor to fair. ${ }^{28,66}$ Lenke, et al. ${ }^{68}$ developed a classification system to address these issues, attempting to satisfy the following: be comprehensive, consider sagittal alignment, define treatment standards, be based on objective criteria, have good inter- and intraobserver reliability, and be easily understood (Fig. 6).

The Lenke classification system is based on standing long-cassette coronal, lateral, and right and left side-bending radiographs. The curves are classified according to curvature type (1-6) combined with a lumbar spine modifier $(\mathrm{A}, \mathrm{B}$, or $\mathrm{C})$ and a sagittal thoracic modifier $(-, \mathrm{N}$, or +$){ }^{68}$ The curvature types are main thoracic, double thoracic, double major, triple major, thoracolumbar/lumbar, and thoracolumbar/lumbar main thoracic. The lumbar spine modifier is based on the relationship of the center sacral vertical line to the lumbar curve observed on the coronal radiograph. The lumbar modifiers quantify the extent of lumbar curve as A (minimal), B (moderate), and C (large). The center sacral vertical line either (A) runs through the lumbar vertebra to the stable vertebrae, (B) runs between the medial border of the lumbar concave pedicle and the concave lateral margin of the apical vertebrae, or (C) falls completely medial to the entire concave lateral aspect of the apical vertebrae. The sagittal thoracic modifier describes overall thoracic kyphosis: hypokyphosis $(-)$, a curve less than $+10^{\circ}$; normal $(\mathrm{N})$, a curve +10 to $+40^{\circ}$; or hyperkyphosis $(+)$, a curve more than $+40^{\circ}$.

Lenke, et al., ${ }^{68}$ reported that the intraobserver reliability 


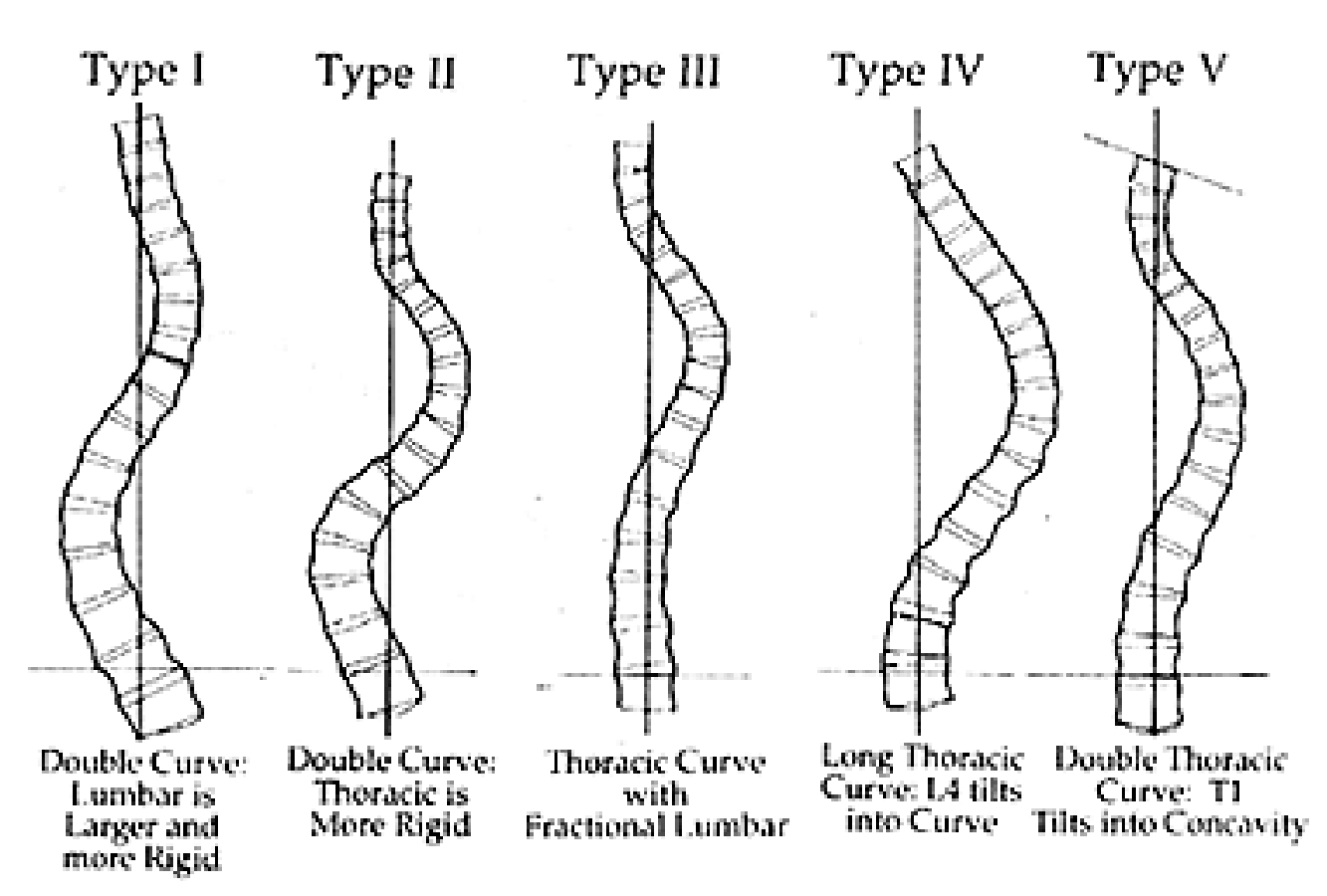

Fig. 5. King classification for idiopathic scoliosis. Used with permission from King, et al., 1983.

was greater than that of the King classification. The authors proposed that only the structural curves need to be fused. In a roundtable discussion format, seven cases were presented to 28 scoliosis surgeons. ${ }^{67}$ There was $84 \%$ agreement on classification of the curve type, $86 \%$ agreement on lumbar modifier, and $90 \%$ agreement on thoracic modifier. When asked to pick the proximal and distal level for fusion, however, the operative approaches used and levels chosen varied widely. There was a mean of five different proximal and four different distal fusion levels chosen for each case. This new classification system seems to address some of the shortcomings of the King classification system. Only time and additional investigation will determine if the new classification will help standardize the assessment and maximize the treatment of AIS.

Brace treatment in cases of AIS is recommended to minimize progression in a growing patient in whom curves are greater than $25^{\circ}$ and less than $40^{\circ} .{ }^{75}$ If a patient is followed at an earlier stage, then brace therapy is instituted if progression (an increase of $\geq 5^{\circ}$ ) beyond $20^{\circ}$ is documented. Adolescents with curves in excess of $45^{\circ}$ should undergo surgery, because even after skeletal maturity curves of this magnitude will likely progress. ${ }^{7,109,110}$ In all cases, brace therapy should be abandoned if several attempts to control progression of deformity have failed.

Lonstein and Winter ${ }^{75}$ reviewed brace treatment in 1020 patients and found that $22 \%$ required surgery. In patients with a curve between 20 to $29^{\circ}, 51 \%$ progressed if the Risser stage was 0 to 1 but only $15 \%$ did so if the Risser stage was greater than 2. Similarly, if the curve was 30 to $39^{\circ}$, deformity in $53 \%$ with a Risser stage of 0 to 1 progressed, whereas in only $25 \%$ with a Risser stage greater than 2 progressed. Nevertheless, these rates of progression were less than those in a similar group in which treatment was not performed. Results in this series confirmed again that the more immature the patient and the greater the curve, the more likely progression will occur.

\section{Early-Onset Scoliosis (Age $<8$ Years)}

Idiopathic scoliosis most commonly develops during late childhood (juvenile type) or adolescence and can create serious cosmetic and functional problems. Pulmonary compromise, however, is an additional concern in the rare cases of scoliosis developing before 5 years of age. ${ }^{29,57}$ According to Nilsonne and Lundgren, ${ }^{89}$ the severe curves $\left(>100^{\circ}\right)$ resulted in death due to cardiac or pulmonary causes in $60 \%$ of their cases. Because idiopathic infantile scoliosis is so rare, meticulous neurological, physical, and radiological examination of these patients is mandatory to exclude congenital or neurological causes of the scoliosis. Routine brainstem and spinal cord MR imaging is reasonable for excluding central nervous system abnormalities such as a syrinx in patients age 8 years or younger who present with a spinal deformity of greater than $20^{\circ} .{ }^{96}$

In comparison with AIS and juvenile idiopathic scoliosis, the curves in infantile scoliosis are commonly (in $50-75 \%$ of patients) left thoracic curves, and boys are more commonly affected than are girls. ${ }^{57}$ Mehta ${ }^{84}$ found that the risk of progression was related to the RVAD. This angle is formed by a line along the rib head and a perpendicular to the base of the apical vertebra (Fig. 7). If the difference between the angles on the concave/convex side exceeds $20^{\circ}$, progression will likely occur. ${ }^{22,84}$

Observation is a reasonable course of action until the curve reaches 30 to $40^{\circ}$, because brace therapy and application of a cast are difficult in small children. ${ }^{57,82}$ Curves less than $35^{\circ}$ with RVAD of less than $20^{\circ}$ have reportedly responded well to brace therapy, whereas those more than $45^{\circ}$ with RVAD greater than $20^{\circ}$ were associated with a poor prognosis. ${ }^{58}$ If the early-onset curve fails to be halted by several attempts at brace therapy, surgery should be considered once the curve exceeds 55 to $60^{\circ}$. The placement of spinal instrumentation without fusion is the preferred procedure in patients younger than 9 years of age. ${ }^{35}$ Once adolescence is reached, anterior instrumentation- 


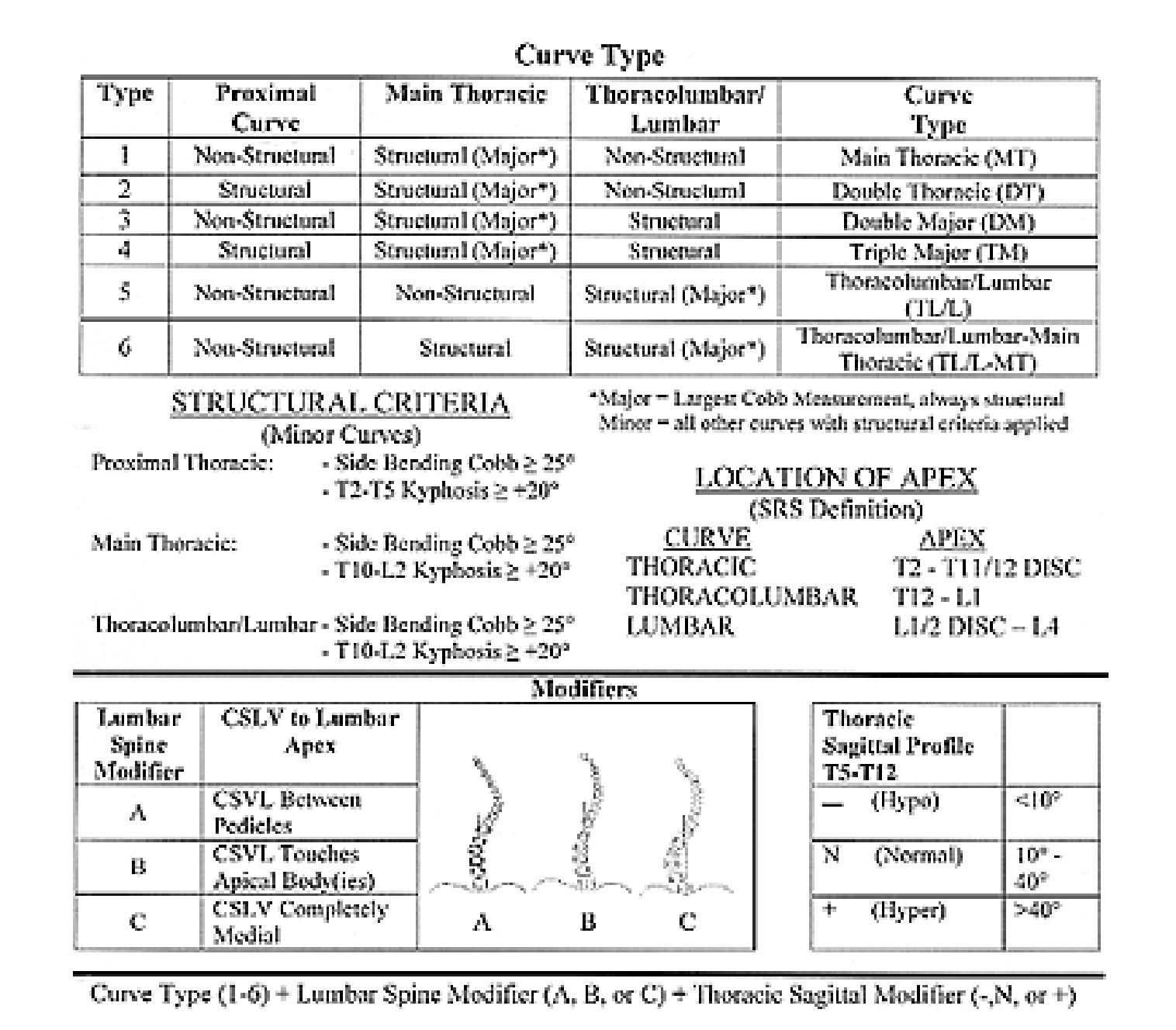

Fig. 6. Classification of AIS devised by Lenke, et al.69 Synopsis of all necessary criteria for curvature classification. SRS = Scoliosis Research Society; CSVL = center sacral vertical line. Used with permission from Lenke, et al., 2001..

assisted fusion may be performed. Complications related to this technique are common and include hook dislodgment, rod breakage, skin breakdown, and early fusion without bone graft.

The crankshaft phenomenon has been used to explain curvature progression in preadolescent patients after posterior instrumentation-assisted fusion. ${ }^{40,41,95}$ Sanders, et al., ${ }^{95}$ analyzed data in 43 patients with idiopathic scoliosis after undergoing this procedure. The crankshaft phenomenon was demonstrated in 11 patients. The authors recommended anterior discectomy to accompany posterior instrumentation and fusion in patients younger than age 10 years, in older premenarchal patients with Risser Stage 0 bone maturity, or in patients in whom the triradiate cartilages are open.

\section{Instrumentation for Spinal Deformity}

Typically, surgical treatment of AIS is accomplished by placing posterior instrumentation and conducting fusion. If the curve exceeds $75^{\circ}$ and cannot be corrected to $50^{\circ}$ as demonstrated on bending radiographs, however, an anterior approach might be considered for improving deformity correction and for enhancing fusion by performing discectomies and releasing the anterior longitudinal lig- ament. Anterior approaches are also used to arrest the growth of the vertebrae in immature patients in whom progression, due to crankshafting, may be a problem. Finally, anterior instrumentation is now being considered for application in patients with lumbar curves or thoracolumbar curves to spare lumbar motion segments (Fig. 8).

Posterior spinal instrumentation for deformity correction has evolved rapidly since the introduction of distraction rods and hooks by Harrington in $1960 .{ }^{51}$ In this evolution the primary emphasis has been on creating more secure fixation and 3D correction. ${ }^{14,15,39,91}$ There are several options for segmental anchors including hooks, wires, and pedicle screws. Varying amounts of rotational, tilting (coronal and sagittal), axial, and translational forces are exerted by the various segmental anchors (Fig. 9). Because the lamina is stronger and closer to the VB center (instantaneous axis of rotation) than is the spinous process, greater translational force can be exerted by sublaminar wires. ${ }^{4,8,36}$ The risk of neurological injury, however, increases with insertion and retrieval of sublaminar wires compared with spinous process wires. ${ }^{11}$

Pedicle screws can produce sagittal-plane tilting, rotation, axial compression or distraction, and translation of instrumented vertebrae. Unlike the use of pedicle hooks, 


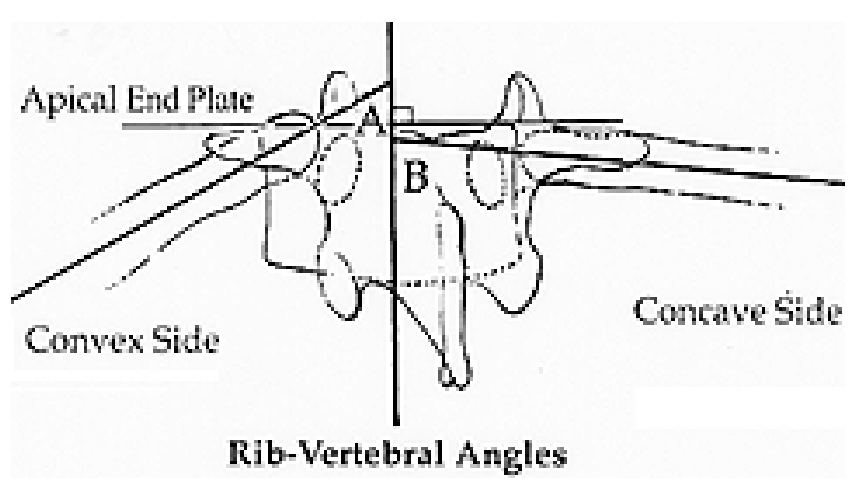

Fig. 7. Posterior view of apical vertebrae from a left thoracic infantile curve. The rib-vertebra angles are formed between the vertebral endplates and a line along the corresponding rib head. If the RVAD is greater than $20^{\circ}$, curve progression is more likely. Data used with permission from Mehta, 1972.

considerable controversy surrounds the use of pedicle screws. Reports of screw breakage, pullout, and attendant neurological injury have resulted in early reappraisal of this implant. Initially pedicle screws were used to anchor the inferior end of the construct in the lumbar pedicles. ${ }^{9,50}$ Because the unique complexity of pediatric thoracic pedicle anatomy has been better understood, thoracic pedicle screws have been used to treat scoliosis (Fig. 3). $.^{90} \mathrm{Al}-$ though potentially dangerous, the authors of several studies have shown that for properly trained spine surgeons, thoracic pedicle screws can be placed safely to treat pediatric deformity. ${ }^{9,16,90,101}$ Additionally, thoracic pedicle screws have higher pullout strength than hooks. ${ }^{69}$ Thoracic pedicle screws have been shown to be safe, have greater deformity correction than hooks, restore thoracic kyphosis in hypokyphotic spines, and potentially decrease the number of levels required for fusion. ${ }^{70,99,100,102,103}$

Deacon and Dickson ${ }^{31}$ and colleagues ${ }^{32}$ and Dickson alone $^{34}$ are credited with the concept that scoliosis is pathological lordosis associated with vertebral rotation; thus, the term lordoscoliosis correctly describes the majority of thoracic curves. With the 3D pathoanatomy in mind, Dubousset and Cotrel $^{39}$ introduced a technique involving insertion of a concave rod, followed by rotation of the rod back to the midline, to convert the lordoscoliosis to pure thoracic kyphosis (Fig. 10). Strategic vertebrae, including the end vertebra and the rigid intermediate vertebra, were instrumented with hooks. Although conceptually correct, the authors of subsequent studies have shown that "derotation" of the vertebrae is limited. ${ }^{14}$ Although some rotation may occur, most of the thoracic correction is achieved by distraction and apical translation.

At approximately the same time that Harrington developed posterior instrumentation for scoliosis correction in the US, Dwyer ${ }^{42}$ in Australia, developed the first anterior system. Dwyer reasoned that better correction could be achieved by instrumenting the VBs after performing an anterior release procedure and discectomy. His anterior approach and the instrumentation (VB screw, staple-andcable construct) were the prototypes for other systems. ${ }^{23,42}$ Newer anterior instrumentation systems for scoliotic deformities are composed of a rod and VB screws. The rigidity of the rods minimizes the common tendency of the Dwyer cables to produce kyphosis. These newer anterior instrumentation systems are ideally suited for lumbar or thoracolumbar scoliosis with a minimal or flexible thoracic curve. In cases involving this curve pattern, posterior construct-assisted L-4 fusion is generally necessary.
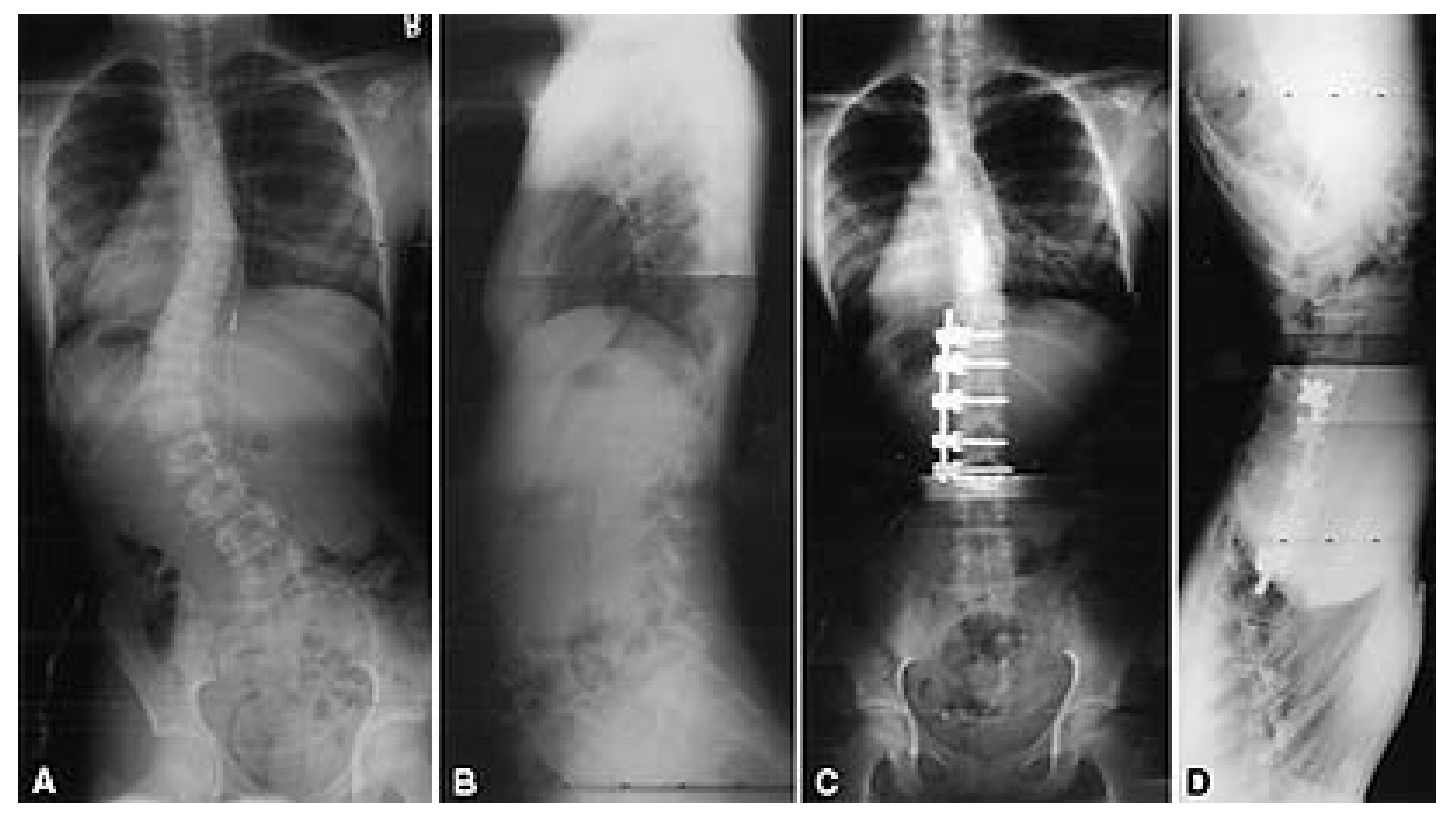

Fig. 8. Radiographs obtained in a 12-year-old girl with King Type I scoliosis. $A$ and $B$ : Preoperative AP and lateral radiographs. Because her thoracic curve was found to be flexible on side-bending radiographs, an anterior approach was performed to save the lumbar motion segments. $\quad C$ and $D$ : Postoperative AP and lateral radiographs demonstrating complete correction of the lumbar curve with maintenance of lumbar lordosis. The patient will need to be followed until her skeleton matures to ensure that the corrected thoracic curve maintains coronal balance. 


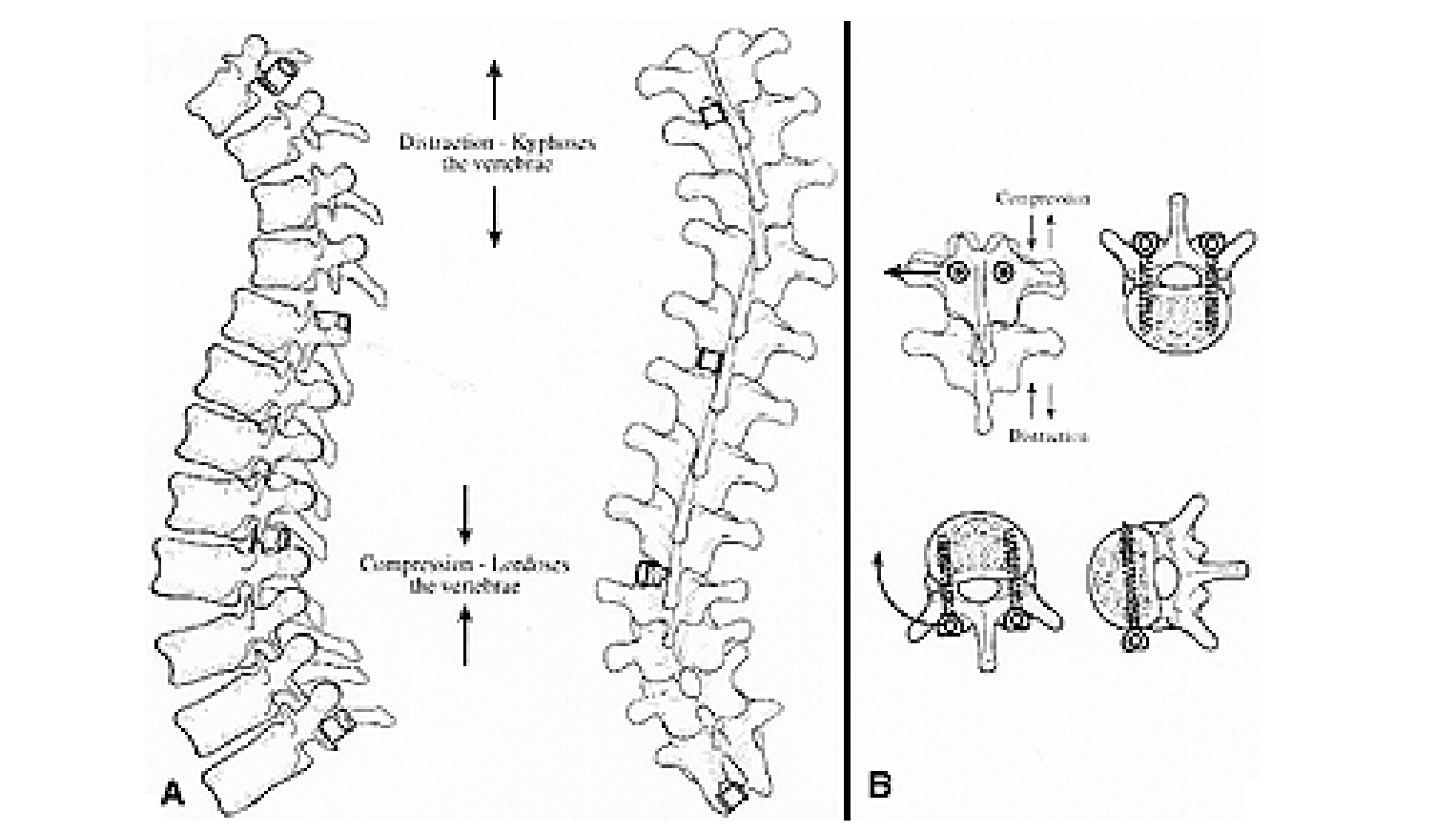

Fig. 9. Implant-derived forces. A: Distraction across the concavity corrects scoliosis and produces kyphosis; similarly, compression across the convexity reduces scoliosis and produces lordosis. B: Hooks and pedicle screws can be used for sagittal or coronal tilting of the vertebrae as the axial force (distraction or compression) is applied; in addition, rotational forces can be exerted using pedicle and VB screws. Image used with permission from Elsevier.

Powerful corrective forces, however, can be exerted when anterior instrumentation is combined with thorough discectomies. In most cases, one lumbar motion segment is spared with the anterior construct.

Open anterior approaches have been the mainstay of anterior spinal surgery. Postoperative pain and pulmonary problems, however, have led to the development of alternatives. Although thoracoscopy was first introduced in the 1920 s, only in the past 20 years has it become popular. ${ }^{56}$ Video-assisted thoracoscopic surgery has widely been accepted for nonspinal surgery since the early 1980s..$^{33,59}$ The advantages of video-assisted thoracoscopic surgery include decreased morbidity, improved cosmesis, and improved shoulder girdle, and chest wall muscle function..$^{52,64}$ The application of this technology to pediatric spinal deformity is relatively recent. This technology does have a significant learning curve. ${ }^{88}$ The authors of several studies have demonstrated that anterior release and discectomy performed either by video-assisted thoracoscopic surgery or by standard thoracotomy produce similar results in terms of spinal mobility. ${ }^{87,105}$ This is an evolving technology that has promise to minimize surgery-related trauma while still making possible anterior release and fusion.

Fixation to the pelvis is indicated when the scoliosis extends to L-5 and includes a fixed spinopelvic deformity. ${ }^{122}$ Hook and rod constructs for pelvic fixation have shown to be subject to failure because the sacral laminae were poorly developed and hook purchase on the ala was inadequate. ${ }^{20,51}$ Currently, four techniques have evolved for fixation of instrumentation to the pelvis. The LuqueGalveston technique, developed by Allen and Ferguson, ${ }^{4,5}$ consists of contoured Luque rods placed between the cortical tables of the ileum. Replacing the intrailiac portion of this technique with a screw has simplified the procedure.
Typically, the Luque-Galveston technique is used for scoliosis in which there is pelvic obliquity (frontal plane). Jackson developed a technique for correction of lumbosacral kyphosis by using fixation within the cortical walls of the sacrum and S-1 pedicle screws to anchor the rods to the sacrum. ${ }^{98}$ When performing the Dunn technique, contoured rods are passed through the S-1 foramen, coming to rest on the anterior sacrum between the internal iliac vessels. ${ }^{80}$ Finally, rod-pedicle fixation is used to span the L5-S1 junction and to stabilize spondylolysis or spondylolisthesis..$^{98}$

\section{CONGENITAL SPINAL DEFORMITIES: SCOLIOSIS, KYPHOSIS, AND LORDOSIS}

The incidence of congenital spinal anomalies is estimated to range from of 0.5 to one per 1000 births; the deformities usually arise as sporadic cases with a $1 \%$ chance of transmission. ${ }^{112,115,119,123}$ When the spinal anomaly is one component of a multisystem anomaly, however, the risk of transmission rises to 5 to $10 \% .{ }^{123} \mathrm{~A}$ wide variety of associated anomalies - renal, cardiac, and intraspinal-can accompany congenital spinal deformities. ${ }^{54,63,81 \text {, }}$ ${ }_{119,120}$ Intraspinal anomalies, such as stenosis, diastematomyelia, and spinal cord tethering occur in 5 to $35 \%$ of congenital spinal deformities. They may be signaled by the presence of posterior midline skin lesions (such as hairy patches or deep dimples), asymmetrical foot deformities (cavus or flat feet), muscle weakness, or spasticity. ${ }^{12,81}$ Sight and hearing can also be congenitally impaired. ${ }^{54}$ All of these systems must be thoroughly examined when a congenital spinal deformity is discovered. Renal ultrasonography, cardiac consultation, and MR imaging of the entire brainstem and spinal cord are essential for complete 


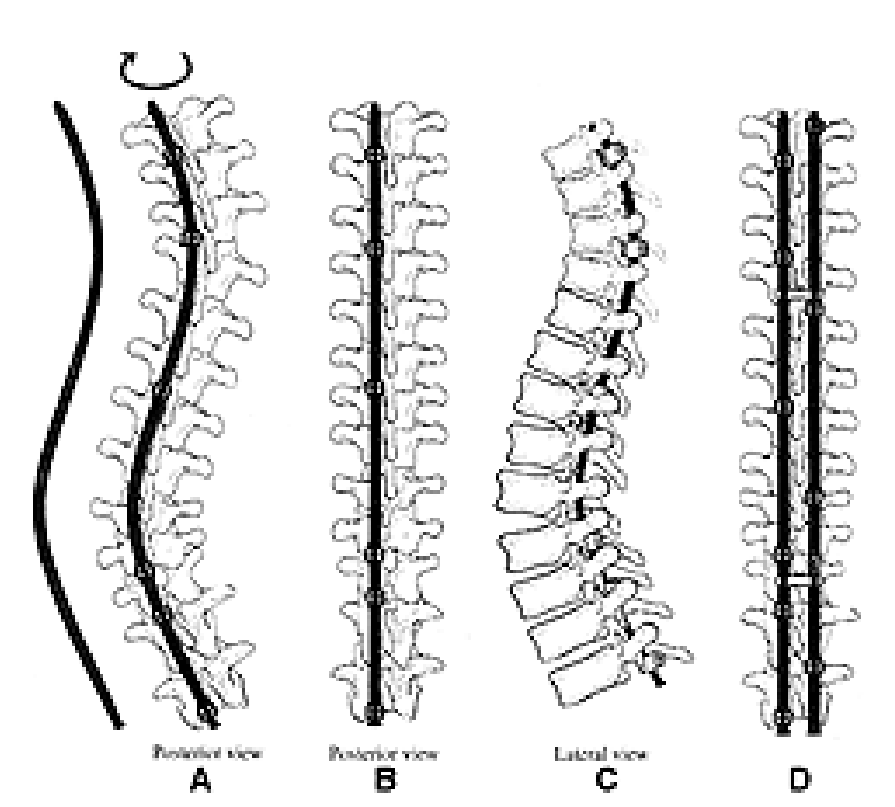

Fig. 10. Scoliosis correction by rod rotation. A: Hooks are placed on the end, intermediate, and apical vertebrae to produce segmental forces. The rod is contoured to fit the scoliotic deformity, placed within the hooks, and rotated to the left. B: This converts the right lordoscoliosis into thoracic kyphosis and the left lumbar scoliosis into lumbar lordosis. Some apical translation occurs with rotation. The downgoing L-3 laminar hook and upgoing L-4 laminar hook produce a claw for enhanced stability. C: The right hooks are inserted to apply compression across the thoracic convexity and lumbar distraction across the concavity. $\mathrm{D}$ : The two rods are linked using two cross-connectors to produce a rigid construct with 10-point fixation to the spine. Image used with permission from Elsevier.

evaluation. Discovery of a defect in an organ system may be more significant for the patient's well-being than is the spinal deformity itself.

The predominant congenital deformity usually exists as a scoliosis, kyphosis, or lordosis. Just as in cases of idiopathic scoliosis, however, most are multiplane deformities. Description of the congenital deformity should include the involved area of the spine, type of vertebral anomaly, and configuration of the deformity, because these factors have implications for evaluation and treatment. ${ }^{83,112,119}$ A classification system for congenital spinal deformities based on the embryological development of the spine was refined by Winter, et al. ${ }^{119}$ In this system $80 \%$ of deformities are classified; however, classification of the remaining $20 \%$ is obscured by the multiplicity of defects. Spinal anomalies are classified as failures of segmentation, failures of formation, and mixed anomalies (Fig. 11). This classification provides a prognostic guide for treatment. In general, 75\% of congenital scoliotic deformities progress, and the rate varies depending on the type.

Defects of segmentation can be uni- or bilateral. A block vertebra is a bilateral segmentation defect that causes the spine to shorten, but it has little propensity for scoliosis progression. Unilateral unsegmented bars, however, have a high frequency of progressing because growth potential exists on only one side of the spine. An unsegmented bar opposite a hemivertebra is associated with the poorest prognosis for rapid progression and should be sur- gically treated at an early stage to prevent severe deformity. In the series described by McMaster and Ohtsuka ${ }^{83}$, these deformities progressed at a rate of least $6^{\circ}$ each year, and all exceeded $50^{\circ}$ by 4 years of age. Early in the course, a segmentation defect can appear as a narrow disc space that progressively narrows with growth until fusion occurs. Defects of formation are those in which absence or maldevelopment of a part of the spine produces deformity. Bifid or absent dorsal elements, hemivertebra, and wedge vertebrae are examples of defects of formation. When spina bifida is associated with defects of the neural elements (meningomyelocele), spasticity and partial paralysis play a major role in the natural history of the spinal deformity. Hemivertebra, another type of formation failure, may involve mild wedging to complete absence of one side of the vertebra. The prognosis varies and is based on the type, location, and number of hemivertebrae. In general, $25 \%$ of hemivertebrae progress rapidly, $25 \%$ do not progress, and $50 \%$ progress slowly. ${ }^{83,117}$ Because the presence of open vertebral growth plates dictates the tendency to progress, the fully segmented hemivertebra, with a functional plate rostrally and caudally, has the greatest propensity to progress. Incarcerated and unsegmented hemivertebrae are rarely associated with progression. Treatment is recommended in cases of severe deformity or when curve documented progression is $10^{\circ}$ or more.

Congenital lordosis is most commonly due to posterior segmentation defects, whereas kyphotic deformities can result from both segmentation defects and failure of formation. Kyphosis resulting from defects of formation manifests as sharper, more angulated deformities that are more likely to evolve such that they induce paraplegia, especially if posterior elements are deficient or if the deformity is in the thoracic spine. ${ }^{117,122}$ Kyphosis secondary to failure of formation (hemivertebra) progresses a mean of $7^{\circ}$ per year. ${ }^{122}$ That resulting from segmentation failure is more rounded, but progressive deformity can still develop. Winter alone $e^{112}$ and with colleagues ${ }^{115}$ estimates that 95\% of congenital kyphoses will progress.

Ideally, surgical fusion is performed early to prevent deformity progression, and correction becomes the goal when patients present later with a severe deformity. Surgical options include 1) posterior fusion, 2) anterior fusion, 3) combined anterior-posterior fusion, 4) hemivertebra excision, and 5) spinal osteotomy and fusion.

Posterior spinal fusion is the gold standard for both congenital scoliosis and kyphosis. By using this approach in 290 cases, Winter, et al., ${ }^{120}$ were able to arrest progression of the curvature in $86 \%$ of cases. To be successful, the posterior fusion must include the entire curve, from stable vertebra to stable vertebra. The crankshaft phenomenon or bending of the posterior fusion mass may occur in some very young patients ( $<5$ years of age) with congenital scoliosis. ${ }^{118}$ In 12 of 32 patients younger than 5 years of age in the Winter series progression occurred after posterior fusion for congenital scoliosis. When thoracic lordosis is part of the deformity, anterior discectomy and fusion are recommended to avoid progressive thoracic encroachment.

In mild cases of congenital kyphosis, spontaneous correction after posterior fusion alone can occur in young patients $(<5$ years of age $)$ with kyphotic deformity less than $50^{\circ} .{ }^{118}$ When the focal kyphosis exceeds $50^{\circ}$, correc- 


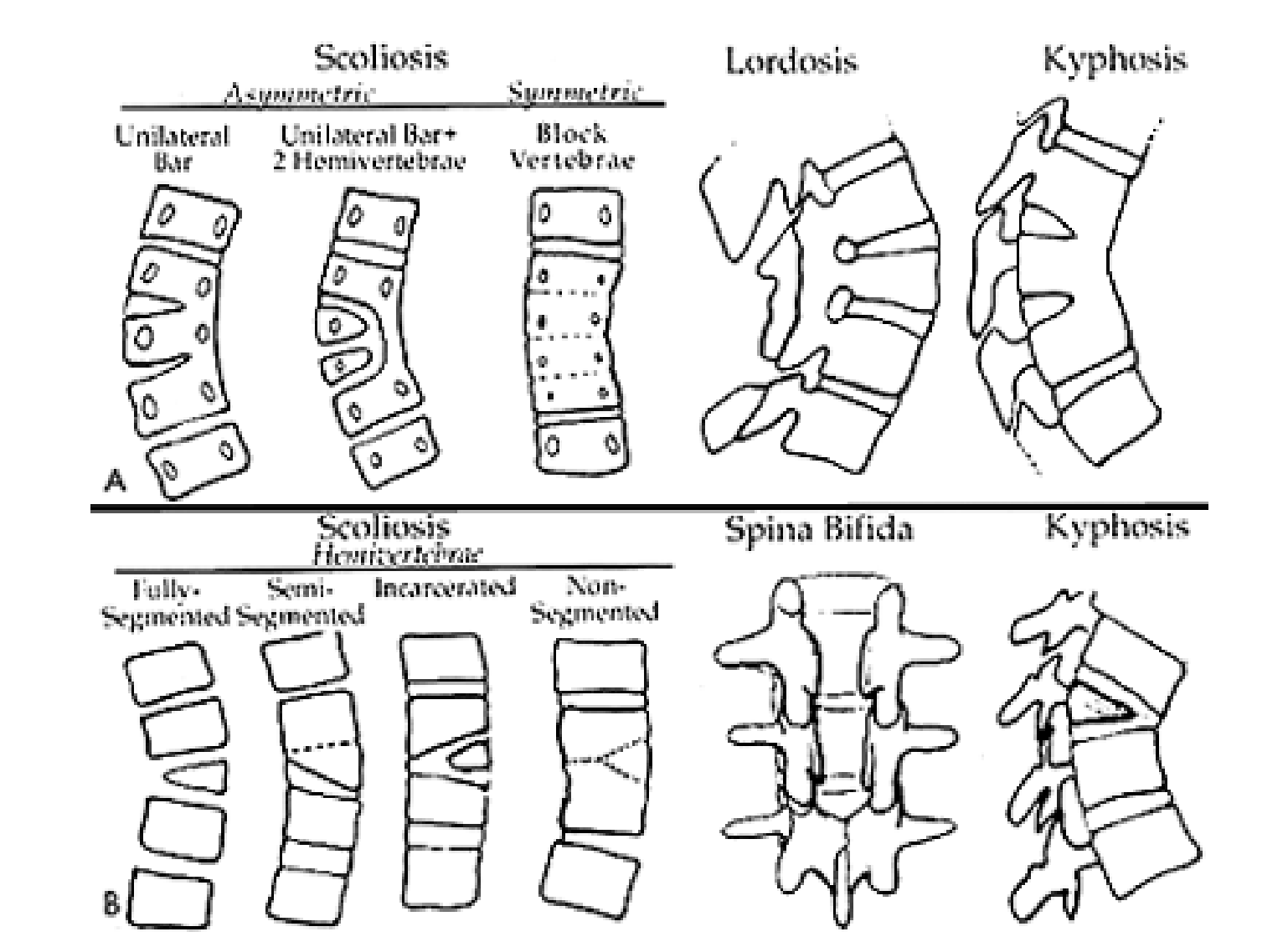

Fig. 11. A: Defects of segmentation. B: Defects of formation. Image used with permission from Elsevier.

tion requires anterior release followed by posterior fusion. If the anterior release is not performed, the pseudarthrosis rate may be as high as 54\% compared with $13 \%$ when combining anterior and posterior fusion. ${ }^{122}$ Winter, et al. ${ }^{122}$ recommended routine reexploration of the posterior bone graft 6 months after a posterior surgery if anterior fusion was not performed. In their series, however, instrumentation was not used.

In 1955, Roaf ${ }^{94}$ described the technique of anterior and posterior convex hemiepiphysiodesis. When congenital scoliosis is due to one or two ipsilateral, fully segmented hemivertebrae, anterior convex discectomy and anterior convex fusion are performed to arrest convex growth and thus potentiate correction by preferential concave growth. ${ }^{6,10}$ Some authors found that the procedure provided the best results in patients younger than 5 years of age in whom curves were less than $40^{\circ} .41,113,115,116$ The technique is not recommended for kyphotic deformities and has limited application in patients older than 5 years of age. Of 13 patients treated by this technique, Winter, et al., ${ }^{116}$ found curvature improvement (a true epiphysiodesis effect) in five patients, fusion with curvature stabilization in seven patients, and failure with progression in one patient (due to inadequate size of the fused area).

Combined anterior-posterior approaches are used to excise hemivertebrae. ${ }^{11,62,65}$ Although thoracic and lumbar resection has been performed, ideally this procedure is reserved for an L-5 lumbosacral junction hemivertebra causing trunk decompensation. Excision of hemivertebrae at other levels is typically reserved for cases of severe kyphotic deformities, which may or may not be associated with neurological defects. In these cases, the excision is performed to decompress the spinal cord that is tented over the apex of the kyphosis. Congenital spinal deformities are rigid, and correction, by whatever means, is achieved through the mobile segments above and below the anomaly. Children tolerate casts well, and satisfactory correction can often be maintained without instrumentation and the attendant risk of SCI.

Instrumentation may be placed to improve or maintain correction of congenital spinal deformities; however, the postoperative risk of neurological impairment is highest in this group. ${ }^{48,114,115}$ The risks are attributable to the small spinal canal size, the severity of deformities, and the frequent presence of intraspinal anomalies such as diastematomyelia or tethering. ${ }^{48}$ Therefore, before a hook or wire is inserted in the spinal canal, MR imaging of the entire spine should be performed. Tethered cords and diastematomyelia must be corrected before instrumentation is placed. Furthermore, instrumentation appropriate to the patient's size must be chosen. Intraoperative spinal cord monitoring is preferred when instrumentation is to be applied.

The superior/inferior endpoints of instrumentation are chosen so that the head is centered over the pelvis in both the frontal and sagittal planes. Examination of bending and traction radiographs can help predict correction and determine the endpoints of instrumentation. The compensatory curve need not be included in the fusion, unless it is anticipated that the structural component of the com- 
pensatory curve is sufficient to cause trunk decompensation. Highly flexible compensatory curves need not be included but must be followed carefully to ensure that progression does not occur postoperatively. If progression is documented and growth continues, then brace therapy until maturity is recommended. Posterior instrumentation is reserved for the thoracic and lumbar deformities in adolescents or in cases in which significant instability is created by combined anterior-posterior osteotomies.

\section{COMPLICATIONS OF SPINAL INSTRUMENTATION AND FUSION}

Since the 1970s, techniques in spine surgery have expanded dramatically. Anterior approaches have become routine, and there has been a burgeoning of instrumentation for correction of deformity. Although the replacement of casts with segmental instrumentation to correct spinal deformity has been a vast improvement, the attendant risks of the surgery have increased. Furthermore, more follow up is needed to determine whether newer constructs will reduce the incidence of lumbar arthritis distal to the end of the constructs. ${ }^{25,27}$ Finally, because spinal deformity can be associated with other organ system compromise, comprehensive preoperative evaluation is mandatory. Even if the patient is a healthy adolescent with idiopathic scoliosis, the magnitude of the surgery results in disturbances of organ systems that must be recognized and managed carefully to avoid complications.

The goal of scoliosis surgery has always been to halt progression by creating bone fusion and to obtain correction of deformity. The surgeon seeks to achieve deformity correction with fusion of as few segments as possible, particularly preserving lumbar vertebrae. Therefore, choosing levels for instrumentation and fusion becomes a critical component of the surgical planning, mistakes in which can result in persistent deformity or trunk decompensation. Spinal levels improperly chosen for instrumentation combined with further spinal growth contribute to the problems of postoperative trunk decompensation and deformity. ${ }^{13,53,61,78}$

Before the era of instrumentation, Hibbs, et al., ${ }^{55}$ performed scoliosis surgery through a window in a cast. All the vertebrae involved in the curve were included in the fusion, and the patients were kept in a cast for a period of 1 year or more until fusion occurred. Moe ${ }^{85}$ popularized the concept that the neutrally rotated vertebrae marked the end of the curve and that fusion must include all the intervening segments. Harrington ${ }^{51}$ introduced posterior distraction instrumentation for scoliosis correction and stated that the instrumentation must end within the stable zone. Harrington, as well as Moe, understood that in some cases the less severe curves (fractional and compensatory curves) did not need to be included in the fusion. For example, in King Type II curves, instrumentation of the thoracic deformity alone led to some spontaneous improvement in the compensatory lumbar curve, thus maintaining trunk balance. King, et al., ${ }^{61}$ reviewed the 149 cases of Moe to assess the effectiveness of these concepts. Frontalplane radiographs were obtained and grouped into five categories. For all curve types, instrumentation extending to the stable vertebrae resulted in optimal frontal-plane balance.
Although their review provided a practical classification system and guidelines for treatment, it has several deficiencies. In all cases Harrington distraction instrumentation, rather than a newer segmental system, was used. Furthermore, spinal flexibility, as demonstrated on sidebending radiographs, did not play an obvious role in the selection of the levels to be fitted with instrumentation. Harrington's technique primarily provided coronal-plane correction by distraction, whereas the newer techniques allow greater apical translation and rotation, thus inducing greater correction of the deformity. Greater correction involves fewer fused segments in some cases, but it may also impart torsional forces in unfused segments, resulting in persistent or new deformity. ${ }^{13}$ Trunk decompensation occurs when correction of the upper spine exceeds the capacity of the lower uninstrumented segments to achieve spontaneous correction. In this situation, the lower spinal segments remain structurally deformed, leaving an oblique take-off from the sacrum. The problem produces cosmetic deformity and theoretically predisposes the patient to arthritis due to asymmetrical loading of the vertebral segments.

Postoperative infections are inevitable in this modern era instrumentation-augmented spinal fusion because of the large amount of metal implanted, including rods, cross-fixators, and multiple hooks. The routine use of perioperative antibiotic agents has limited the incidence of infection for idiopathic cases to approximately one per 100 cases, whereas in neuromuscular cases the rate rises to approximately $5 \% .^{73,104}$ In patients with meningomyelocele the infection rate is approximately $10 \%$. Factors predisposing to infection include development of a hematoma, poor skin condition (meningomyelocele), concurrent infections such as urinary tract infection, and poor nutrition. To some extent, all these factors can be controlled.

Persistent fever associated with a temperature greater than $101.5^{\circ} \mathrm{F}$ after the 5th postoperative day should heighten suspicions of an acute wound infection. Evaluation includes a comprehensive culture of tissues including blood, urine, pulmonary fluids, and wound aspirates. A purulent aspirate or a persistent large hematoma should be aggressively treated by irrigation in the operating room. Prompt irrigation should be followed by administration of parenteral antibiotic agents until culture results have been obtained. If an established infection is found, any loose bone graft should be removed. Most surgeons perform closure over a drain. Other options include closure over a close suction-irrigation system or leaving the wound open to allow packing and subsequent healing by secondary intention. The latter method is generally reserved when the other options fail. Similarly, the duration of antibiotic therapy and the route of administration will vary. Commonly, parenteral antibiotic therapy for at least 3 weeks, followed by oral administration for 3 weeks, is prescribed. The sedimentation rate is a useful marker to follow; however, the level may not normalize for several weeks after treatment of the acute inflammation. Therefore, undertreatment is unlikely when using this parameter as a guide.

Delayed infections are now well recognized after spinal surgery. ${ }^{92}$ Affected patients present with back pain and signs of inflammation or drainage months to years after such surgery. The most common organisms are Staphylo- 
coccus epidermidis, Propionibacterium acnes, and other skin flora. These organisms of low virulence are believed to contaminate the wound at the time of surgery, and infection remains subclinical for an extended period..$^{92}$ Treatment of these infections should follow the same guidelines as for acute infections. Aggressive irrigation and debridement followed by wound drainage is the first treatment. Healing by secondary intention may be necessary for failure of the initial attempts.

Although bleeding is an obvious consequence of spinal surgery, the routine use of hypotensive anesthesia as well as frames to suspend the abdomen can reduce bleeding. Nevertheless, bleeding from the decorticated bone surfaces will continue postoperatively, and the placement of closed wound drains is a prudent measure to reduce hematoma formation. Generally, drainage tapers off after 36 hours, and the drains are removed. Persistent bleeding may reflect uncorrected coagulopathy. If blood loss is expected to exceed $1000 \mathrm{ml}$, intraoperative cell savers should be used.

Spinal instrumentation has enhanced the spine surgeon's ability to achieve correction of deformities. Halting progression and maintaining correction, however, ultimately depend on achieving an osseous fusion. Factors impeding fusion include the source of the bone graft, surgical techniques, magnitude of the deformity, and healing potential of the patient. In most cases of spinal surgery, there is a race with time between the fatigue life of the implants and the formation of a solid fusion mass.

One or more of the following symptoms and signs usually indicate the presence of a pseudarthrosis: pain, progressive deformity, or implant failure (rod breakage or hook pullout). Imaging studies such as computerized tomography or bone scanning can be conducted to confirm the diagnosis and the location of the pseudarthrosis. ${ }^{104}$ When signs of pseudarthrosis are present, exploration and grafting of the defect are recommended. The defect is usually be found in the area of tension. Treatment entails removal of all fibrous tissue, placement of a copious bone graft, and application of instrumentation designed to produce compression across the site. Cultures are obtained routinely because of the high association between infections and pseudarthroses.

Before instrumentation was introduced for spinal deformity correction, surgery-induced neurological injury was rare. Neurological complications are the inevitable consequence of more invasive techniques. The exact incidence can only be estimated. The Scoliosis Research Society, however, surveyed its members in 1993 and reported a $0.6 \%$ incidence of neurological injury associated with scoliosis correction and a $1.4 \%$ incidence associated with all categories of spinal deformity. The vast majority of cases involved nerve root damage, and most patients recovered. Cases of complete or partial SCI, however, were reported. Thus, an understanding of the risk factors and avoidance techniques is crucial to minimizing this complication.

Neurological injury is secondary to direct trauma, such as that induced by hooks, screws, wires, or bone impingement of the spinal cord and from indirect injury due to excessive distraction or ischemia. A combination of both direct and indirect mechanisms may also be responsible for such injury in some cases. Because of these factors, methods to monitor spinal cord function intraoperatively are important when performing deformity correction.

In 1973, Vauzelle and Stagnara introduced the wake-up test to confirm spinal cord conduction after application of instrumentation. ${ }^{49}$ To perform the test, anesthesia is reduced until a patient can follow commands to move his feet. When both feet move, the anesthesia is increased, and the procedure is completed. Associated complications include extubation and air embolisms. Furthermore, because incomplete, subtle neurological deficits can be missed, this technique is not applicable in neuromuscular cases.

Direct monitoring of spinal cord function is the other method for intraoperative confirmation of spinal cord conduction. ${ }^{111}$ Presently, posterior column function is monitored using recording somatosensory evoked potentials. Stimulating electrodes are placed over peripheral nerves in the lower extremities and recording is conducted through scalp, neck, or spinous process electrodes. A positive result is considered to be an acute change of $50 \%$ in amplitude or $15 \%$ in latency. False results (both false positive and false negative) can occur if the core temperature drops or if the level of halogenated anesthetic agents become too high. ${ }^{2}$ Clearly, factors involving the surgeon and technician affect the utility of evoked potential monitoring. Concomitant monitoring of anterior column function (motor evoked potentials) is another alternative but is technically challenging.

If a neurological complication is suspected based on an abnormal wake-up test result, immediate correction of hypotension and release of distraction should be undertaken. ${ }^{49}$ If the wake-up test continues to indicate abnormality, removal of the instrumentation is recommended. Similarly, if evoked potentials remain abnormal after correction of physiological parameters, distraction should be relieved and implants should be removed to restore spinal cord function. Often, with an acute change in the evoked potentials, reversal of the previous step (removal of a hook or reduction of distraction) will restore the potentials. The ability to monitor continuously is a major advantage of evoked potential monitoring over the wake-up test.

Patient-related factors associated with increased neurological complications include kyphosis (congenital or otherwise), congenital deformity, neurofibromatosis, sublaminar wires, rigid curves, and combined anterior-posterior approaches. ${ }^{77}$ Kyphotic deformities induce the spinal cord to stretch. Therefore, compression or shortening of the spinal column should be undertaken for correction. ${ }^{122}$ In cases of congenital deformities there is a high incidence of occult intraspinal anomalies that can lead to SCI if these problems are not addressed before scoliosis is corrected. ${ }^{81}$ The tight angular curves associated with neurofibromatosis put the spinal cord at risk. In addition, neurofibromas may occupy space within the spinal canal, producing a relative stenosis. Both insertion and removal of sublaminar wires is associated with a higher incidence of neurological complications compared with hook and rod systems. ${ }^{111}$ Finally, severe deformities requiring a combined anterior-posterior approach are more likely to result in neurological deficits. Spinal cord ischemia may play a role in the pathophysiology. Therefore, if possible, the goal should be to spare the segmental vessels. 


\section{CONCLUSIONS}

The evaluation and treatment of pediatric spinal deformities is challenging. Detailed knowledge is required of the different types of deformity and their propensity for progression and possible attendant neurological compromise. Each class of deformity presents challenges in management. Recent advances in spinal instrumentation and techniques have allowed greater correction of deformities but also have increased the associated risks. A new classification system for AIS potentially will aid in treatment. In this article we have detailed some of the history of pediatric deformity while highlighting recent additions to the field.

\section{Acknowledgments}

The authors wish to thank Smith, Nephew, Richard's Spine Division for assistance with preparation of artwork. Much of this work was based on a previous book chapter by the authors ${ }^{3}$ and was used with permission.

\section{Disclaimer}

The views expressed in this paper are those of the authors and do not reflect the official policy or position of the US Government, Department of Defense, or Department of the Air Force.

\section{References}

1. Aaro S, Ohlund C: Scoliosis and pulmonary function. Spine 9:220-222, 1984

2. Abel MF, Mubarak SJ, Wenger DR, et al: Brainstem evoked potentials for scoliosis surgery: a reliable method allowing use of halogenated anesthetic agents. J Pediatr Orthop 10:208-213, 1990

3. Abel MF, Shaffrey CI, Menezes AH: Pediatric Spinal Deformities, in Benzel EC (ed): Spine Surgery: Techniques, Complication Avoidance, and Management. Philadelphia: ChurchillLivingstone, 1999, pp 565-612

4. Allen BL Jr, Ferguson RL: The Galveston technique for L rod instrumentation of the scoliotic spine. Spine 7:276-284, 1982

5. Allen BL Jr, Ferguson RL: The Galveston technique of pelvic fixation with L-rod instrumentation of the spine. Spine 9: 388-394, 1984

6. Andrew T, Piggott H: Growth arrest for progressive scoliosis. Combined anterior and posterior fusion of the convexity. $\mathbf{J}$ Bone Joint Surg Br 67:193-197, 1985

7. Ascani E, Bartolozzi P, Logroscino CA, et al: Natural history of untreated idiopathic scoliosis after skeletal maturity. Spine 11: 784-789, 1986

8. Asher MA, Strippgen WE, Heinig CF, et al: Isola instrumentation, in Weinstein SL (ed): The Pediatric Spine: Principles and Practice. New York: Raven Press, 1994, pp 1619-1658

9. Barr SJ, Schuette AM, Emans JB: Lumbar pedicle screws versus hooks. Results in double major curves in adolescent idiopathic scoliosis. Spine 22:1369-1379, 1997

10. Bradford DS: Partial epiphyseal arrest and supplemental fixation for progressive correction of congenital spinal deformity. J Bone Joint Surg Am 64:610-614, 1982

11. Bradford DS, Boachie-Adjei O: One-stage anterior and posterior hemivertebral resection and arthrodesis for congenital scoliosis. J Bone Joint Surg Am 72:536-540, 1990

12. Bradford DS, Heithoff KB, Cohen M: Intraspinal abnormalities and congenital spine deformities: a radiographic and MRI study. J Pediatr Orthop 11:36-41, 1991

13. Bridwell K: Adolescent idiopathic scoliosis: surgical treatment, in Weinstein SL (ed): The Pediatric Spine: Principles and Practice. New York, Raven Press, 1994, pp 511-556
14. Bridwell KH, Betz R, Capelli AM, et al: Sagittal plane analysis in idiopathic scoliosis patients treated with Cotrel-Dubousset instrumentation. Spine 15:921-926, 1990

15. Bridwell KH, McAllister JW, Betz RR, et al: Coronal decompensation produced by Cotrel-Dubousset "derotation" maneuver for idiopathic right thoracic scoliosis. Spine 16:769-777, 1991

16. Brown CA, Lenke LG, Bridwell KH, et al: Complications of pediatric thoracolumbar and lumbar pedicle screws. Spine 23: 1566-1571, 1998

17. Bunnell WP: The natural history of idiopathic scoliosis. Clin Orthop 229:20-25, 1988

18. Bunnell WP, MacEwen GD: Non-operative treatment of scoliosis in cerebral palsy: preliminary report on the use of a plastic jacket. Dev Med Child Neurol 19:45-49, 1977

19. Bunnell WP, MacEwen GD, Jayakumar S: The use of plastic jackets in the non-operative treatment of idiopathic scoliosis. Preliminary report. J Bone Joint Surg Am 62:31-38, 1980

20. Camp JF, Caudle R, Ashmun RD, et al: Immediate complications of Cotrel-Dubousset instrumentation to the sacro-pelvis. A clinical and biomechanical study. Spine 15:932-941, 1990

21. Carr WA, Moe JH, Winter RB, et al: Treatment of idiopathic scoliosis in the Milwaukee brace. J Bone Joint Surg Am 62: 599-612, 1980

22. Ceballos T, Ferrer-Torrelles M, Castillo F, et al: Prognosis in infantile idiopathic scoliosis. J Bone Joint Surg Am 62: $863-875,1980$

23. Chan DP: Zielke instrumentation. Instr Course Lect 32: 208-209, 1983

24. Chapman EM, Dill DB, Graybiel A: The decrease in functional capacity of the lungs and heart resulting from deformities of the chest: pulmonocardiac failure. Medicine 18:167-202, 1939

25. Cochran T, Irstam L, Nachemson A: Long-term anatomic and functional changes in patients with adolescent idiopathic scoliosis treated by Harrington rod fusion. Spine 8:576-584, 1983

26. Collis DK, Ponseti IV: Long-term follow-up of patients with idiopathic scoliosis not treated surgically. J Bone Joint Surg Am 51:425-445, 1969

27. Connolly PJ, Von Schroeder HP, Johnson GE, et al: Adolescent idiopathic scoliosis. Long-term effect of instrumentation extending to the lumbar spine. J Bone Joint Surg Am 77: 1210-1216, 1995

28. Cummings RJ, Loveless EA, Campbell J, et al: Interobserver reliability and intraobserver reproducibility of the system of King et al. for the classificaiton of adolescent idiopathic scoliosis. J Bone Joint Surg Am 80:1107-1111, 1998

29. Davies G, Reid L: Effect of scoliosis on growth of alveoli and pulmonary arteries and on right ventricle. Arch Dis Child 46: 623-632, 1971

30. Deacon P, Archer IA, Dickson RA: The anatomy of spinal deformity: a biomechanical analysis. Orthopedics 10: 897-903, 1987

31. Deacon P, Dickson RA: Vertebral shape in the median sagittal plane in idiopathic thoracic scoliosis. A study of true lateral radiographs in 150 patients. Orthopedics 10:893-895, 1987

32. Deacon P, Flood BM, Dickson RA: Idiopathic scoliosis in three dimensions. A radiographic and morphometric analysis. J Bone Joint Surg Br 66:509-512, 1984

33. DeCamp MM Jr, Jaklitsch MT, Mentzer SJ, et al: The safety and versatility of video-thoracoscopy: a prospective analysis of 895 consecutive cases. J Am Coll Surg 181:113-120, 1995

34. Dickson RA: The aetiology of spinal deformities. Lancet 1: 1151-1155, 1988

35. Dickson RA: Early-onset idiopathic scoliosis, in Weinstein SL (ed): The Pediatric Spine: Practice and Principles. New York: Raven Press, 1994, pp 421-430

36. Dickson RA, Archer IA: Surgical treatment of late-onset idiopathic thoracic scoliosis. The Leeds procedure. J Bone Joint Surg Br 69:709-714, 1987 
37. Dimeglio A, Bonnel F: Growth of the spine, in Raimondi AJ, Choux M, Di Rocco C (eds): The Pediatric Spine. New York: Springer-Verlag, 1989, pp 39-83

38. Dubousset J: Three-dimensional analysis of the scoliotic deformity, in Weinstein SL (ed): The Pediatric Spine: Principles and Practice. New York: Raven Press, 1994, pp 479-496

39. Dubousset J, Cotrel Y: Application technique of Cotrel-Dubousset instrumentation for scoliosis deformities. Clin Orthop 264:103-110, 1991

40. Dubousset J, Herring JA, Shufflebarger H: The crankshaft phenomenon. J Pediatr Orthop 9:541-550, 1989

41. Dubousset J, Katti E, Seringe R: Epiphysiodesis of the spine in young children for congenital spinal deformities. J Pediatr Orthop 1B:123-130, 1993

42. Dwyer AF: Experience of anterior correction of scoliosis. Clin Orthop 93:191-214, 1973

43. Emans JB, Kaelin A, Bancel P, et al: The Boston bracing system for idiopathic scoliosis. Follow-up results in 295 patients. Spine 11:792-801, 1986

44. Federico DJ, Renshaw TS: Results of treatment of idiopathic scoliosis with the Charleston bending orthosis. Spine 15: 886-887, 1990

45. Goldstein LA, Waugh TR: Classification and terminology of scoliosis. Clin Orthop 93:10-22, 1973

46. Green NE: Part-time bracing of adolescent idiopathic scoliosis. J Bone Joint Surg Am 68:738-742, 1986

47. Hadley-Miller N, Mims B, Milewicz DM: The potential role of the elastic fiber system in adolescent idiopathic scoliosis. J Bone Joint Surg Am 76:1193-1206, 1994

48. Hall JE, Herndon WA, Levine CR: Surgical treatment of congenital scoliosis with or without Harrington instrumentation. J Bone Joint Surg Am 63:608-619, 1981

49. Hall JE, Levine CR, Sudhir KG: Intraoperative awakening to monitor spinal cord function during Harrington instrumentation and spine fusion. Description of procedure and report of three cases. J Bone Joint Surg Am 60:533-536, 1978

50. Hamill CL, Lenke LG, Bridwell KH, et al: The use of pedicle screw fixation to improve correction in the lumbar spine of patients with idiopathic scoliosis. Is it warranted? Spine 21: 1241-1249, 1996

51. Harrington PR: Technical details in relation to the successful use of instrumentation in scoliosis. Orthop Clin North Am 3:49-67, 1972

52. Hazelrigg SR, Landreneau RJ, Boley TM, et al: The effect of muscle-sparing versus standard posterolateral thoracotomy on pulmonary function, muscle strength, and postoperative pain. J Thorac Cardiovasc Surg 101:394-401, 1991

53. Hefti FL, McMaster MJ: The effect of the adolescent growth spurt on early posterior spinal fusion in infantile and juvenile idiopathic scoliosis. J Bone Joint Surg Br 65:247-254, 1983

54. Hensinger RN, Lang JE, MacEwen GD: Klippel-Feil syndrome; a constellation of associated anomalies. J Bone Joint Surg Am 56:1246-1253, 1974

55. Hibbs RA, Risser JC, Ferguson AB: Scoliosis treated by the fusion operation: an end-result study of three hundred and sixty cases. J Bone Joint Surg 13:91-104, 1931 (Reference unverified)

56. Jacobeaus HC: The cauterization of adhesions in pneumothorax treatment of tuberculosis. Surg Gynecol Obstet 32:493-500, 1921 (Reference unverified)

57. James JIP, Lloyd-Roberts GC, Pilcher MF: Infantile structural scoliosis. J Bone Joint Surg Br 41:719-735, 1959

58. Kahanovitz N, Levine DB, Lardone J: The part-time Milwaukee brace treatment of juvenile idiopathic scoliosis. Long-term follow-up. Clin Orthop:145-151, 1982

59. Kaiser LR: Video-assisted thoracic surgery. Current state of the art. Ann Surg 220:720-734, 1994

60. Kindsfater K, Lowe T, Lawellin D, et al: Levels of platelet calmodulin for the prediction of progression and severity of ado- lescent idiopathic scoliosis. J Bone Joint Surg Am 76: 1186-1192, 1994

61. King HA, Moe JH, Bradford DS, et al: The selection of fusion levels in thoracic idiopathic scoliosis. J Bone Joint Surg Am 65:1302-1313, 1983

62. King JD, Lowery GL: Results of lumbar hemivertebral excision for congenital scoliosis. Spine 16:778-782, 1991

63. Kuhns JG, Hormell RS: Management of congenital scoliosis: review of one hundred seventy cases. Arch Surg 65:250-263, 1952 (Reference unverified)

64. Landreneau RJ, Hazelrigg SR, Mack MJ, et al: Postoperative pain-related morbidity: video-assisted thoracic surgery versus thoracotomy. Ann Thorac Surg 56:1285-1289, 1993

65. Leatherman KD, Dickson RA: Two-stage corrective surgery for congenital deformities of the spine. J Bone Joint Surg Br 61:324-328, 1979

66. Lenke LG, Betz RR, Bridwell KH, et al: Intraobserver and interobserver reliability of the classification of thoracic adolescent idopathic scoliosis. J Bone Joint Surg Am 80: 1097-1106, 1998

67. Lenke LG, Betz RR, Haher TR, et al: Multisurgeon assessment of surgical decision-making in adolescent idiopathic scoliosis: curve classification, operative approach, and fusion levels. Spine 26:2347-2353, 2001

68. Lenke LG, Betz RR, Harms J, et al: Adolescent idiopathic scoliosis: a new classification to determine extent of spinal arthrodesis. J Bone Joint Surg Am 83:1169-1181, 2001

69. Liljenqvist U, Hackenberg L, Link T, et al: Pullout strength of pedicle screws versus pedicle and laminar hooks in the thoracic spine. Acta Orthop Belg 67:157-163, 2001

70. Liljenqvist UR, Halm HF, Link TM: Pedicle screw instrumentation of the thoracic spine in idiopathic scoliosis. Spine 22: 2239-2245, 1997

71. Lonstein JE: Embryology and spinal growth, in Lonstein JE, Winter RB, Bradford DS, et al: Moe's Textbook of Scoliosis and other Spinal Deformities, ed 3. Philadelphia: W.B. Saunders, 1995, pp 23-38

72. Lonstein JE: Patient evaluation, in Lonstein JE, Winter RB, Bradford DS, et al: Moe's Textbook of Scoliosis and other Spinal Deformities, ed 3. Philadelphia: W.B. Saunders, 1995, pp 45-86

73. Lonstein JE, Akbarnia A: Operative treatment of spinal deformities in patients with cerebral palsy or mental retardation. An analysis of one hundred and seven cases. J Bone Joint Surg Am 65:43-55, 1983

74. Lonstein JE, Carlson JM: The prediction of curve progression in untreated idiopathic scoliosis during growth. J Bone Joint Surg Am 66:1061-1071, 1984

75. Lonstein JE, Winter RB: The Milwaukee brace for the treatment of adolescent idiopathic scoliosis. A review of one thousand and twenty patients. J Bone Joint Surg Am 76:1207-1221, 1994

76. Lonstein JE, Winter RB, Bradford DS, et al: Moe's Textbook of Scoliosis and other Spinal Deformities, ed 3. Philadelphia: W.B. Saunders, 1995

77. Lonstein JE, Winter RB, Moe JH, et al: Neurologic deficits secondary to spinal deformity. A review of the literature and report of 43 cases. Spine 5:331-355, 1980

78. Mason DE, Carango P: Spinal decompensation in Cotrel-Dubousset instrumentation. Spine 16 (Suppl 8):394-403, 1991

79. McCarthy RE: Evaluation of the patient with deformity, in Weinstein SL (ed): The Pediatric Spine: Principles and Practice. New York: Raven Press, 1994, pp 185-224

80. McCarthy RE, Dunn H, McCullough FL: Luque fixation to the sacral ala using the Dunn-McCarthy modification. Spine 14: 281-283, 1989

81. McMaster MJ: Occult intraspinal anomalies and congenital scoliosis. J Bone Joint Surg Am 66:588-601, 1984

82. McMaster MJ, Macnicol MF: The management of progressive 
infantile idiopathic scoliosis. J Bone Joint Surg Br 61: 36-42, 1979

83. McMaster MJ, Ohtsuka K: The natural history of congenital scoliosis. A study of two hundred and fifty-one patients. J Bone Joint Surg Am 64:1128-1147, 1982

84. Mehta MH: The rib-vertebra angle in the early diagnosis between resolving and progressive infantile scoliosis. J Bone Joint Surg Br 54:230-243, 1972

85. Moe JH: Methods of correction and surgical techniques in scoliosis. Orthop Clin North Am 3:17-48, 1972

86. Moe JH, Kharrat K, Winter RB, et al: Harrington instrumentation without fusion plus external orthotic support for the treatment of difficult curvature problems in young children. Clin Orthop 185:35-45, 1984

87. Newton PO, Cardelia JM, Farnsworth CL, et al: A biomechanical comparison of open and thoracoscopic anterior spinal release in a goat model. Spine 23:530-535, 1998

88. Newton PO, Shea KG, Granlund KF: Defining the pediatric spinal thoracoscopy learning curve: sixty-five consecutive cases. Spine 25:1028-1035, 2000

89. Nilsonne U, Lundgren KD: Long-term prognosis in idiopathic scoliosis. Acta Orthop Scand 39:456-465, 1968

90. O'Brien MF, Lenke LG, Mardjetko S, et al: Pedicle morphology in thoracic adolescent idiopathic scoliosis: is pedicle fixation an anatomically viable technique? Spine 25:2285-2293, 2000

91. Phillips WA, Hensinger RN: Wisconsin and other instrumentation for posterior spinal fusion. Clin Orthop 229:44-51, 1988

92. Richards BS: Delayed infections following posterior spinal instrumentation for the treatment of idiopathic scoliosis. J Bone Joint Surg Am 77:524-529, 1995

93. Risser JC, Norquist DM, Cockrell BR Jr, et al: The effect of posterior spine fusion on the growing spine. Clin Orthop 46: 127-139, 1966

94. Roaf R: Wedge resection for scoliosis. J Bone Joint Surg Br 37:99-101, 1955 (Reference unverified)

95. Sanders JO, Herring JA, Browne RH: Posterior arthrodesis and instrumentation in the immature (Risser-grade-0) spine in idiopathic scoliosis. J Bone Joint Surg Am 77:39-45, 1995

96. Schwend RM, Hennrikus W, Hall JE, et al: Childhood scoliosis: clinical indications for magnetic resonance imaging. J Bone Joint Surg Am 77:46-53, 1995

97. Shufflebarger HL: Theory and mechanisms of posterior derotation spinal systems, in Weinstein SL (ed): The Pediatric Spine: Principles and Practice. New York: Raven Press, 1994, pp 1515-1544

98. Stefee A, Edwards CC, Yuan HA, et al: Spondylolisthesis: posterior instrumentation, in Brown CW (ed): Spinal Instrumentation Techniques. Rosemont: Scoliosis Research Society, 1994

99. Suk SI, Kim WJ, Kim JH, et al: Restoration of thoracic kyphosis in the hypokyphotic spine: a comparison between multiplehook and segmental pedicle screw fixation in adolescent idiopathic scoliosis. J Spinal Disord 12:489-495, 1999

100. Suk SI, Kim WJ, Lee CS, et al: Indications of proximal thoracic curve fusion in thoracic adolescent idiopathic scoliosis: recognition and treatment of double thoracic curve pattern in adolescent idiopathic scoliosis treated with segmental instrumentation. Spine 25:2342-2349, 2000

101. Suk SI, Kim WJ, Lee SM, et al: Thoracic pedicle screw fixation in spinal deformities: are they really safe? Spine 26: 2049-2057, 2001

102. Suk SI, Lee CK, Kim WJ, et al: Segmental pedicle screw fixation in the treatment of thoracic idiopathic scoliosis. Spine 20: 1399-1405, 1995

103. Suk SI, Lee CK, Min HJ, et al: Comparison of Cotrel-Dubousset pedicle screws and hooks in the treatment of idiopathic scoliosis. Int Orthop 18:341-346, 1994
104. Trendwell SJ: Complications of Spinal Surgery, in Weinstein SL (ed): The Pediatric Spine: Principles and Practice. New York: Raven Press, 1994, pp 1761-1786

105. Wall EJ, Bylski-Austrow DI, Shelton FS, et al: Endoscopic discectomy increases thoracic spine flexibility as effectively as open discectomy. A mechanical study in a porcine model. Spine 23:9-16, 1998

106. Weinstein SL: Adolescent idiopathic scoliosis: prevalence and natural history, in Weinstein SL (ed): The Pediatric Spine: Principles and Practice. New York: Raven Press, 1994, pp 463-478

107. Weinstein SL: Idiopathic scoliosis. Natural history. Spine 11: 780-783, 1986

108. Weinstein SL: The Pediatric Spine: Principles and Practice. New York: Raven Press, 1994, Vol 1

109. Weinstein SL, Ponseti IV: Curve progression in idiopathic scoliosis. J Bone Joint Surg Am 65:447-455, 1983

110. Weinstein SL, Zavala DC, Ponseti IV: Idiopathic scoliosis: long-term follow-up and prognosis in untreated patients. J Bone Joint Surg Am 63:702-712, 1981

111. Wilber RG, Thompson GH, Shaffer JW, et al: Postoperative neurological deficits in segmental spinal instrumentation. A study using spinal cord monitoring. J Bone Joint Surg Am 66:1178-1187, 1984

112. Winter RB: Congenital Deformities of the Spine. New York: Thieme-Stratton, 1983

113. Winter RB: Convex anterior and posterior hemiarthrodesis and hemiepiphyseodesis in young children with progressive congenital scoliosis. J Pediatr Orthop 1:361-366, 1981

114. Winter RB, Leonard AS: Surgical correction of congenital thoracic lordosis. J Pediatr Orthop 10:805-808, 1990

115. Winter RB, Lonstein JE, Boachie-Adjei O: Congenital spinal deformity. Instr Course Lect 45:117-127, 1996

116. Winter RB, Lonstein JE, Denis F, et al: Convex growth arrest for progressive congenital scoliosis due to hemivertebrae. J Pediatr Orthop 8:633-638, 1988

117. Winter RB, Lonstein JE, Drogt J, et al: The effectiveness of bracing in the nonoperative treatment of idiopathic scoliosis. Spine 11:790-791, 1986

118. Winter RB, Moe JH: The results of spinal arthrodesis for congenital spinal deformity in patients younger than five years old. J Bone Joint Surg Am 64:419-432, 1982

119. Winter RB, Moe JH, Eilers VE: Congenital scoliosis: a study of 234 patients treated and untreated. Part 2 Treatment. J Bone Joint Surg Am 50:1-15, 1968

120. Winter RB, Moe JH, Lonstein JE: Posterior spinal arthrodesis for congenital scoliosis. An analysis of the cases of two hundred and ninety patients, five to nineteen years old. J Bone Joint Surg Am 66:1188-1197, 1984

121. Winter RB, Moe JH, MacEwen GD, et al: The Milwaukee brace in the non-operative treatment of congenital scoliosis. Spine 1:85-96, 1976

122. Winter RB, Moe JH, Wang JF: Congenital kyphosis. Its natural history and treatment as observed in a study of one hundred and thirty patients. J Bone Joint Surg Am 55:223-256, 1973

123. Wynne-Davies R: Congenital vertebral anomalies: aetiology and relationship to spina bifida cystica. J Med Genet 12: 280-288, 1975

124. Wynne-Davies R: Familial (idiopathic) scoliosis. A family survey. J Bone Joint Surg Br 50:24-30, 1968

Manuscript received November 25, 2002.

Accepted in final form December, 11, 2002.

No financial support was received in relation to this manuscript.

Address reprint requests to: Gregory C. Wiggins, M.D., 901

Sapphire Circle, Vacaville, California 65687. email: gcwiggins@ yahoo.com. 